Research Article

\title{
A State Feedback Controller Based on GCC Algorithm against Wind-Induced Motion for High-Rise Buildings with Parametric Uncertainties
}

\author{
Zuohua Li $\oplus,{ }^{1}$ Chaojun Chen $\left(\mathbb{1},{ }^{1}\right.$ Jun Teng $\oplus,{ }^{1}$ Junkai Dong, ${ }^{1}$ and Beichun Lin ${ }^{2}$ \\ ${ }^{1}$ School of Civil and Environmental Engineering, Harbin Institute of Technology Shenzhen, Shenzhen 518055, China \\ ${ }^{2}$ Shenzhen Baoan Drainage Co., Ltd, Shenzhen, China \\ Correspondence should be addressed to Chaojun Chen; chenchaojun@hit.edu.cn
}

Received 26 March 2019; Accepted 4 June 2019; Published 14 July 2019

Academic Editor: Giuseppe Petrone

Copyright (C) 2019 Zuohua Li et al. This is an open access article distributed under the Creative Commons Attribution License, which permits unrestricted use, distribution, and reproduction in any medium, provided the original work is properly cited.

\begin{abstract}
High-rise buildings with an active mass damper/driver (AMD) system generally use a simplified mathematical model. The result leads to parametric uncertainties including the stiffness and mass variations exist, and the accuracy of its controller is seriously affected. In view of the above uncertainties, based on a Lyapunov stability theory and linear matrix inequality (LMI) approach, a state feedback controller based on the guaranteed cost control (GCC) algorithm is proposed in this paper. A ten-storey frame with an AMD system is taken as a numerical example, and its control effect and AMD parameters are viewed as the control indexes. The performance of the proposed robust controller is compared with a conventional controller based on the classical LQR algorithm. The analysis results show that the new controller effectively suppresses the dynamic responses of high-rise buildings with parametric uncertainties and keeps the AMD parameters stable. Finally, a four-storey steel experimental frame with an AMD system is used to verify the correctness of the conclusions.
\end{abstract}

\section{Introduction}

A passive tuned mass damper (TMD) [1-3] and an active mass damper/driver (AMD) [4-7] are usually used to suppress the horizontal dynamic responses of high-rise buildings against an environmental loading such as strong winds and earthquakes. As a TMD control system is relatively simple, economic, and reliable, the practical applications of TMDs are more extensive than those of AMDs. However, because the key parameters of a TMD system are difficult to be changed, the control performance of an AMD system is better than that of a TMD system theoretically [8]. Many studies focus on active control systems. For instance, the experimental validation built the foundation for structural vibration control utilizing an innovative electromagnetic mass driver system in [5]. Combining the simulation analysis and physical test, an AMD subsystem testing method was proposed in [6].
Furthermore, the linear quadratic regulator (LQR) algorithm is a common design method of AMD control systems $[9,10]$, but it requires the accurate mathematical model of a target building. When parametric uncertainties exist [11], the optimal controller based on nominal structural parameters often fails to guarantee the stability and expected performance of a closed-loop system [12]. Therefore, it is necessary to design a robust controller to compensate parametric uncertainties.

In practical engineering, $\mathrm{H}_{\infty}$ control theory was widely used to design a compensation control gain for uncertain stochastic systems [13-15]. $\mathrm{H}_{\infty}$ control did not depend on the accuracy of a mathematical model. It mainly considered the robust stability of a control system, but it sacrificed its control performance. The guaranteed cost control (GCC) algorithm [16] is a special LQR control method and is widely used in the fields of electronics, aerospace, mechanical engineering, 
automation, etc. It combined the performance and robustness of the uncertain systems with time delay $[17,18]$. The control algorithm keeps a closed-loop system stable under allowable parametric uncertainties, and its quadratic index is less than a performance limit. A guaranteed cost controller not only solves the defect of the classical LQR algorithm but also possesses the characteristics of clear physical meaning.

In order to successfully apply the GCC algorithm for high-rise buildings with an AMD system, a key step involves solving a positive-definite solution of Riccati matrix equations. Before implementation, several key parameters needed to be determined beforehand. However, effective methods for searching for the optimal values of these parameters are still lacked. The only method that determined parameters artificially is conservative. Moreover, the solving process is based on a Riccati equation method previously, whose convergence cannot be guaranteed [19-21]. Combined with a linear matrix inequality (LMI) approach [22], the Riccati matrix equations could be solved easily [23]. Several above references also indicated that a LMI approach was widely applied to analyze the stability of the control systems with time-delay [24, 25] or design time-delay compensation controllers $[26,27]$. Although the timevarying delay compensation was considered in a GCC system [28], structural parametric uncertainties including stiffness and mass variations reduced the performance of the control system. Therefore, combining the GCC algorithm and LMI approach, a robust guaranteed cost controller is needed to enhance the performance and robustness of the systems with parametric uncertainties, and appropriate weight matrices should be selected to combine the robustness with the control performance.

In this paper, a controller based on the classical LQR algorithm is proposed for a ten-storey frame with an accurate mathematical model, and then the selection of the weight matrices is discussed. On this basis, focusing on this ten-storey frame with parametric uncertainties including the stiffness and mass variations, a new robust control system is designed based on the GCC algorithm. The control effects and AMD parameters are viewed as the control indexes to analyze the performance of the above controller. Finally, an experiment of a four-storey frame is presented to validate the effectiveness of the proposed method.

\section{Optimizing the Parameters Based on the Classical LQR Algorithm}

The force equilibrium of a multi-degree-of-freedom (MDOF) control system without parametric uncertainties is as follows:

$$
\begin{aligned}
& M_{0} \ddot{X}+C_{0} \dot{X}+K_{0} X=B_{w} w+B_{s} u \text {, } \\
& X=\left[\begin{array}{c}
x_{s 1} \\
x_{s 2} \\
\vdots \\
x_{s n} \\
x_{a}
\end{array}\right] \\
& M_{0}=\left[\begin{array}{ccccc}
m_{1} & 0 & 0 & 0 & 0 \\
0 & m_{2} & 0 & 0 & 0 \\
0 & 0 & \ddots & 0 & 0 \\
0 & 0 & 0 & m_{n} & 0 \\
0 & 0 & 0 & 0 & m_{\mathrm{a}}
\end{array}\right] \text {, } \\
& C_{0}=\left[\begin{array}{ccccc}
c_{1}+c_{2} & -c_{2} & 0 & 0 & 0 \\
-c_{2} & c_{2}+c_{3} & \ddots & 0 & 0 \\
0 & \ddots & \ddots & -c_{n} & 0 \\
0 & 0 & -c_{n} & c_{n}+c_{a} & -c_{a} \\
0 & 0 & 0 & -c_{a} & c_{a}
\end{array}\right] \text {, } \\
& K_{0}=\left[\begin{array}{ccccc}
k_{1}+k_{2} & -k_{2} & 0 & 0 & 0 \\
-k_{2} & k_{2}+k_{3} & \ddots & 0 & 0 \\
0 & \ddots & \ddots & -k_{n} & 0 \\
0 & 0 & -k_{n} & k_{n}+k_{a} & -k_{a} \\
0 & 0 & 0 & -k_{a} & k_{a}
\end{array}\right] \text {, } \\
& B_{s}=\left[\begin{array}{c}
0 \\
\vdots \\
0 \\
-1 \\
1
\end{array}\right] \text {, } \\
& B_{w}=\left[\begin{array}{ccccc}
1 & 0 & 0 & 0 & 0 \\
0 & 1 & 0 & 0 & 0 \\
0 & 0 & \ddots & 0 & 0 \\
0 & 0 & 0 & 1 & 0 \\
0 & 0 & 0 & 0 & 1
\end{array}\right] \text {. }
\end{aligned}
$$

where $M_{0}, C_{0}$, and $K_{0}$ are the nominal mass, damping, and stiffness matrices, respectively. $m_{i}, k_{i}$, and $c_{i}$ are the mass, interstory stiffness, and damping of the $i$ th floor $(i=1,2$, $\ldots, n)$, respectively. $m_{a}, c_{a}$, and $k_{a}$ are the mass, damping, and stiffness of a single auxiliary mass, respectively. $X$ is the displacement responses relative to the ground. $x_{s i}$ are the relative displacements of the $i$ th floor $(i=1,2, \ldots, n)$, and $x_{a}$ is the relative displacement of a single auxiliary mass. $u$ and $w$ are the control force and external 
excitation vectors, respectively. $B_{s}$ and $B_{w}$ are the position matrices of the control forces and external excitations, respectively.

Equation (1) is expressed into the state-space equation as

$$
\dot{Z}=A Z+B_{1} w+B_{2} u
$$

where $Z$ is the state vector of a control system that includes the displacement and velocity responses. $A, B_{1}$, and $B_{2}$ are the state matrix, the excitation matrix, and the control matrix, which can be expressed as

$$
\begin{aligned}
A & =\left[\begin{array}{cc}
0 \\
-\left(M_{0}\right)^{-1} K_{0} & -\left(M_{0}\right)^{-1} C_{0}
\end{array}\right], \\
B_{1} & =\left[\begin{array}{c}
0 \\
\left(M_{0}\right)^{-1} B_{w}
\end{array}\right], \\
B_{2} & =\left[\begin{array}{c}
0 \\
\left(M_{0}\right)^{-1} B_{s}
\end{array}\right] .
\end{aligned}
$$

The control force is

$$
u=-G Z
$$

where $G$ is the feedback gain matrix, which is calculated by the classical LQR algorithm.

The follow function is used to solve the solution:

$$
G=\operatorname{lqr}\left(A, B_{2}, Q, R\right),
$$

where $Q$ is a symmetric and semidefinite positive matrix for the state vectors and $R$ is a symmetric and definite positive matrix for the control force vectors.

The weight matrices $Q$ and $R$ are two important parameters of a control system. The selection of the weight matrices reflects the importance attached to the contradictory requirements of the safety and economy of a control system. Through adjusting the weight matrices, an appropriate gain was selected to minimize the performance index under the condition of satisfying the state-space equation and its constraints. Then, the optimal control forces could be determined.

The quadratic performance index is defined as

$$
J(t)=\frac{1}{2} \int_{t_{0}}^{\infty}\left(Z^{T} Q Z+u^{T} R u\right) d t,
$$

in which with the increase of the weight matrix $R$, the control force decreases. If the structural responses are expected to decrease, then the weight matrix $Q$ needs to increase. The elements in $Q$ reflect the importance of each component in the state vectors.

Substituting equation (4) into equation (2) leads to

$$
\dot{Z}=\left(A-B_{2} G\right) Z+B_{1} w \text {. }
$$

A ten-storey frame is used as an example for numerical analysis [29]. The lumped mass method is used to build the mass matrix for the frame. The stiffness matrix can be easily obtained by a flexibility method, as the inverse of the flexibility matrix. The AMD control system with a weight of 4 tons is assumed to be installed on the $8^{\text {th }}$ floor and is only used to control the horizontal vibration along the minor axis. In the paper, a ten-year return period fluctuating wind load is generated for the objective frame. Its wind speed is based on the Davenport spectrum, and a mixed autoregressive-moving average (MARMA) model [30] is used to simulate its stochastic process.

The controller based on the classical LQR algorithm is designed for the frame. Focusing on the control effects to the $8^{\text {th }}$ floor and the strokes of the auxiliary mass, the suitable weight matrices $Q$ and $R$ are selected. Specifically, the weight coefficient $Q_{8}$ corresponding to the displacements of the $8^{\text {th }}$ floor and the weight coefficient $Q_{11}$ corresponding to the strokes of the auxiliary mass are finally determined, and other weight coefficients are set to one. The weight coefficients $Q_{11}$ and $R$ are firstly set to $4 \times 10^{2}$ and $1 \times 10^{-3}$, and the key AMD parameters, including the control forces and strokes, are selected reasonably by analyzing the change of the performance index under different $Q_{8}$ values. The change situations of the control effects to the $8^{\text {th }}$ floor and the AMD parameters with the increase of the $Q_{8}$ are shown in Figure 1. As the $Q_{8}$ reflects the importance of the displacement component to the $8^{\text {th }}$ floor in the state vectors, the control effects to the $8^{\text {th }}$ floor increase gradually with the increase of the $Q_{8}$, and the control forces and strokes have the same trend. Considering the control effects and economic index, the $Q_{8}$ is set to $6 \times 10^{4}$. With the change of the $Q_{11}$, the control effects to the $8^{\text {th }}$ floor and the AMD parameters are shown in Figure 2. As the $Q_{11}$ reflects the importance of the stroke component in the state vectors, the AMD parameters decrease gradually with the increase of the $Q_{11}$, and the control effects to the $8^{\text {th }}$ floor also decrease. Considering the control effects and economic index, the $Q_{11}$ is set to $3 \times 10^{2}$. With the change of the $R$, the control effects to the $8^{\text {th }}$ floor and the AMD parameters are shown in Figure 3. As the $R$ reflects the importance of the economy to the control system, the AMD parameters decrease gradually with the increase of the $R$, and the control effects to the $8^{\text {th }}$ floor also decrease. Considering the control effects and economic index, the $R$ is set to $1 \times 10^{-3}$.

Based on the above analysis, the $Q_{8}, Q_{11}$, and $R$ are set to $6 \times 10^{4}, 3 \times 10^{2}$, and $1 \times 10^{-3}$, respectively. Under a ten-year return period wind load [31], the structural responses to the $8^{\text {th }}$ floor and AMD parameters are shown in Figure 4 . The corresponding control effects and AMD parameters are listed in Table 1. In this paper, the control effect is quantified as the ratio between structural response reduction and the structural response without control, and the AMD parameters include the control forces and strokes. From Figure 4 and Table 1, the LQR control system can obviously reduce the wind vibration responses. Due to the selected weight matrices, the control effects to the $8^{\text {th }}$ floor are optimized firstly, in which its control effects are more obvious and better than that of the upper floors.

\section{A Compensation Controller for the Systems with Parametric Uncertainties}

3.1. Design Principle of the GCC System. The force equilibrium of an AMD control system with uncertain mass and stiffness is 


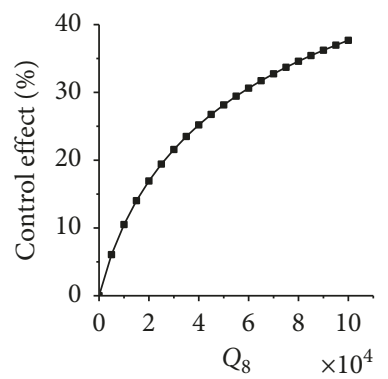

(a)

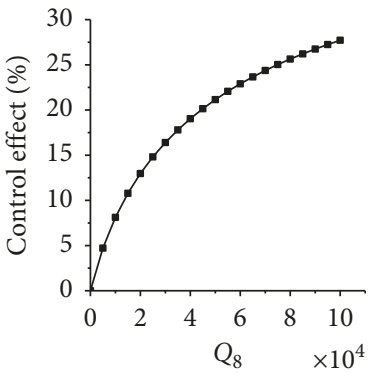

(b)

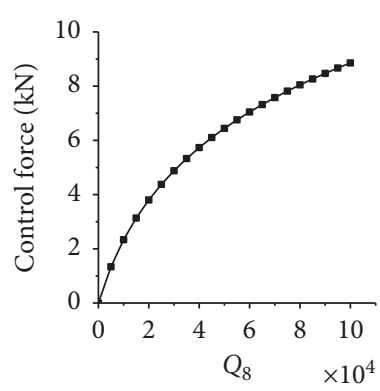

(c)

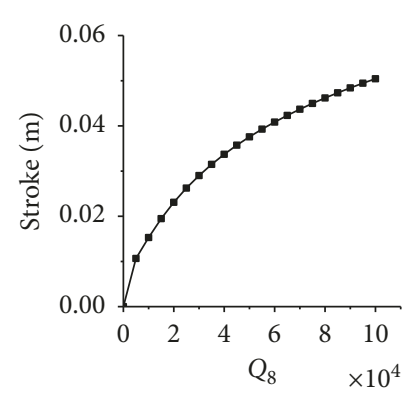

(d)

FIGURE 1: Relationship curves between the control indexes and the weighted coefficient $Q_{8}$ : (a) displacement control effects; (b) acceleration control effects; (c) control forces; (d) strokes.

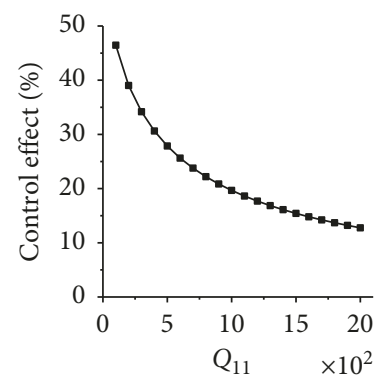

(a)

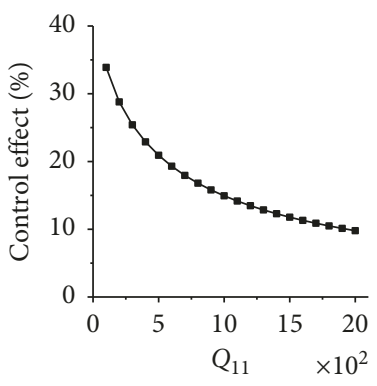

(b)

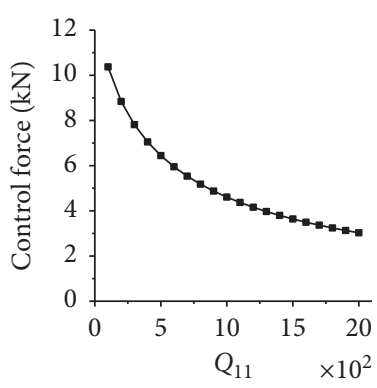

(c)

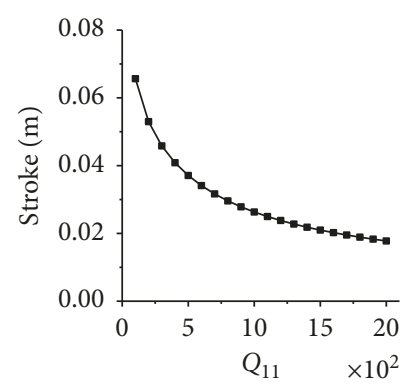

(d)

Figure 2: Relationship curves between the control indexes and the weighted coefficient $Q_{11}$ : (a) displacement control effects; (b) acceleration control effects; (c) control forces; (d) strokes.

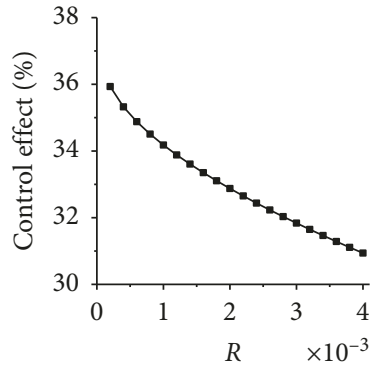

(a)

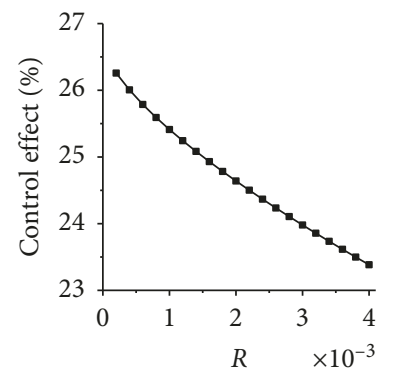

(b)

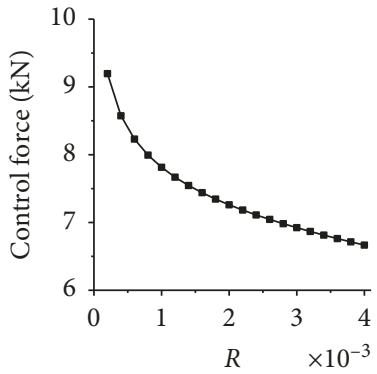

(c)

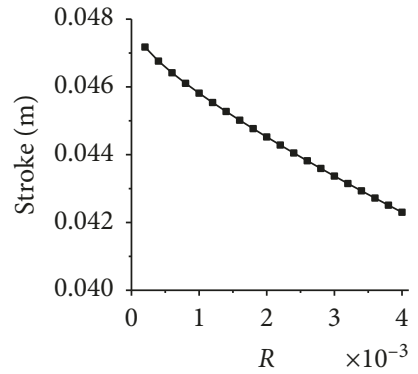

(d)

FIGURE 3: Relationship curves between the control indexes and the weighted coefficient $R$ : (a) displacement control effects; (b) acceleration control effects; (c) control forces; (d) strokes.

$$
\left(M_{0}+\Delta M\right) \ddot{X}+C_{0} \dot{X}+\left(K_{0}+\Delta K\right) X=B_{w} w+B_{s} u,
$$

where $\Delta M$ and $\Delta K$ are the uncertain quantities of the mass and stiffness matrices, respectively. The above parameters can be expressed as

$$
\begin{gathered}
M^{\prime}=M_{0}+\Delta M=\left(1+\delta_{M}\right) M_{0}, \\
K^{\prime}=K_{0}+\Delta K=\left(1+\delta_{K}\right) K_{0},
\end{gathered}
$$

where $\delta_{M}$ and $\delta_{K}$ are the variation coefficients of structural mass and stiffness, respectively.
When the control forces and external excitations are considered separately, the state equation of the system with uncertain parameters are assumed as

$$
\dot{Z}=(A+\Delta A) Z+\left(B_{1}+\Delta B_{1}\right) w+\left(B_{2}+\Delta B_{2}\right) u,
$$

where $\Delta A, \Delta B_{1}$, and $\Delta B_{2}$ are the matrices representing parametric uncertainties in the system.

The perturbation matrix is assumed to be the following form as described in [32]:

$$
\left[\begin{array}{ll}
\Delta A & \Delta B_{2}
\end{array}\right]=D F\left[\begin{array}{ll}
E_{1} & E_{2}
\end{array}\right]
$$



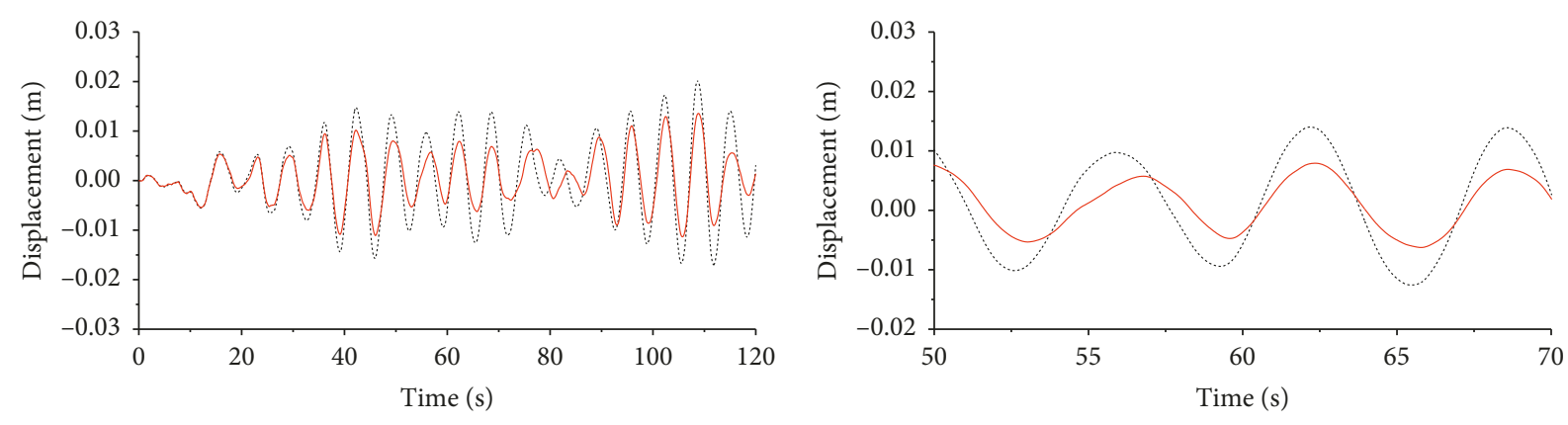

-..-.-. No control

LQR control

(a)

----- No control

__ LQR control

(b)

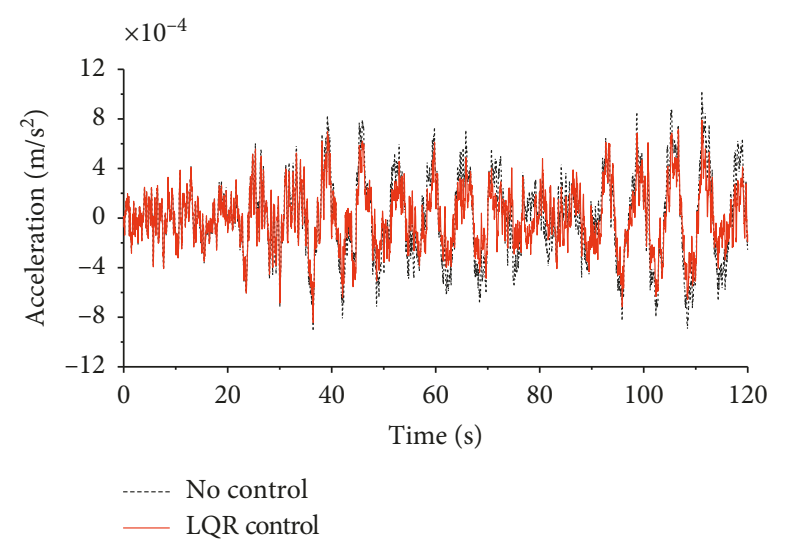

(c)

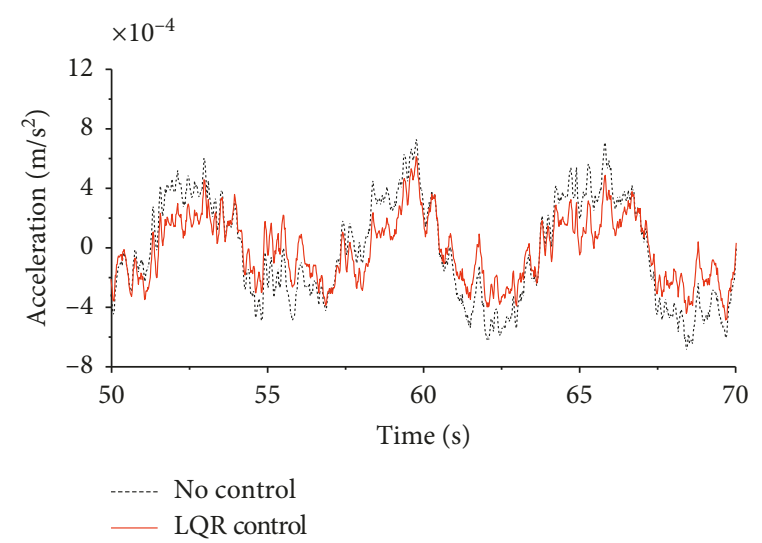

(d)

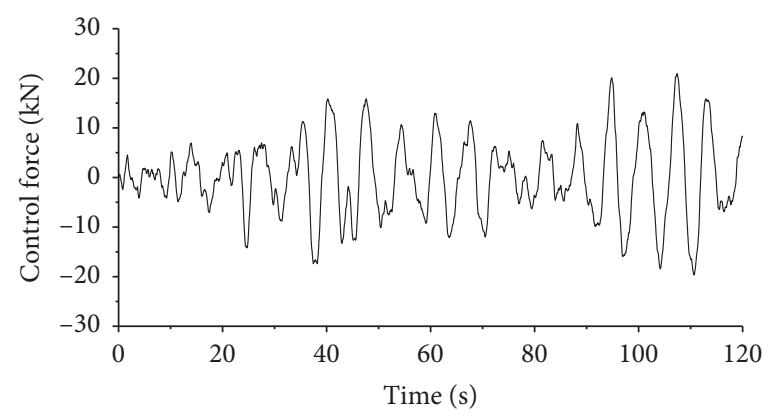

(e)

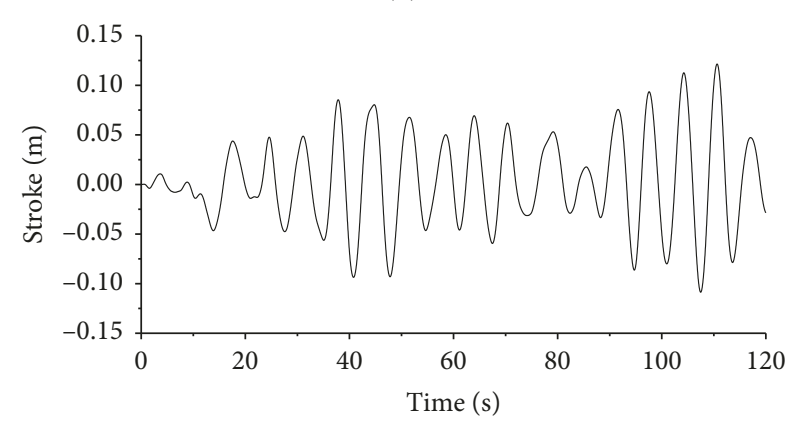

(f)

FIgURE 4: Comparison of the structural responses to the $8^{\text {th }}$ floor and the AMD parameters of the LQR system: (a) 0-120 s and (b) 50-70 s displacements; (c) 0-120 s and (d) 50-70 s accelerations; (e) control forces; (f) strokes.

TABLE 1: Control effects to the structural responses of the frame without variations under LQR control.

\begin{tabular}{|c|c|c|c|c|}
\hline \multirow{2}{*}{\multicolumn{2}{|c|}{ Index }} & \multicolumn{3}{|c|}{ LQR control } \\
\hline & & No control & Control & Effect $(\%)$ \\
\hline \multirow{3}{*}{ Displacement (mm) } & $8^{\text {th }}$ floor & 7.91 & 5.21 & 34.18 \\
\hline & $9^{\text {th }}$ floor & 8.39 & 5.52 & 34.15 \\
\hline & $10^{\text {th }}$ floor & 8.69 & 5.72 & 34.10 \\
\hline \multirow{3}{*}{ Velocity $(\mathrm{mm} / \mathrm{s})$} & $8^{\text {th }}$ floor & 1.52 & 1.00 & 34.42 \\
\hline & $9^{\text {th }}$ floor & 1.62 & 1.07 & 33.90 \\
\hline & $10^{\text {th }}$ floor & 1.69 & 1.13 & 33.17 \\
\hline \multirow{3}{*}{ Acceleration $\left(\mathrm{mm} / \mathrm{s}^{2}\right)$} & $8^{\text {th }}$ floor & 0.33 & 0.24 & 25.41 \\
\hline & $9^{\text {th }}$ floor & 0.36 & 0.27 & 24.11 \\
\hline & $10^{\text {th }}$ floor & 0.41 & 0.33 & 19.46 \\
\hline Control force $(\mathrm{kN})$ & & - & 7.81 & - \\
\hline Stroke $(\mathrm{cm})$ & & - & 4.58 & - \\
\hline
\end{tabular}


where $F$ is an uncertain matrix satisfying $F=\bar{\delta} I,|\bar{\delta}|<1$, and $\bar{\delta}$ is a uncertain constant. And

$$
\begin{aligned}
& D=\left[\begin{array}{cc}
0 & 0 \\
-\frac{K_{0}}{M_{0}} & -\frac{C_{0}}{M_{0}}
\end{array}\right], \\
& E_{2}=\left[\begin{array}{c}
0 \\
\frac{B_{s}\left[\left(\delta_{M}+1\right)^{-1}-1\right]}{C_{0}}
\end{array}\right] \text {, } \\
& E_{1}=\left[\begin{array}{cc}
\delta_{K}+\left(\delta_{K}+1\right)\left[\left(\delta_{M}+1\right)^{-1}-1\right] & 0 \\
0 & \left(\delta_{M}+1\right)^{-1}-1
\end{array}\right] \text {. }
\end{aligned}
$$

Substituting equation (11) into equation (10) leads to

$$
\dot{Z}=\left(A-B_{2} G+D F E_{1}-D F E_{2} G\right) Z+\left(B_{1}+\Delta B_{1}\right) w .
$$

Let $\widetilde{A}=A-B_{2} G+D F E_{1}-D F E_{2} G$. When the input excitation is not considered temporarily, the closed-loop system is

$$
\dot{Z}=\widetilde{A} Z \text {. }
$$

For the uncertain system (14), the following inequality is satisfied:

$$
Q+(-G)^{T} R(-G)+\tilde{A}^{T} P+P \widetilde{A}<0 .
$$

where $G$ is a closed-loop feedback gain matrix for system (14).

Lyapunov function $V(Z)=Z^{T} P Z$, where $P$ is the positive-definite matrix and $\dot{V}(Z)$ is the derivative of $V(Z)$ with respect to time. According to the algorithms of the transport matrix,

$$
\begin{aligned}
\dot{V}(Z) & =\dot{Z}^{T} P Z+Z^{T} P \dot{Z}=(\widetilde{A} Z)^{T} P Z+Z^{T} P(\widetilde{A} Z) \\
& =Z^{T} \widetilde{A}^{T} P Z+Z^{T} P \widetilde{A} Z \\
& =Z^{T}\left(\widetilde{A}^{T} P+P \widetilde{A}\right) Z .
\end{aligned}
$$

According to inequality (15),

$$
\dot{V}(Z)<Z^{T}\left[Q+(-G)^{T} R(-G)\right] Z<0 .
$$

Based on a Lyapunov stability theory [33], system (14) is asymptotically stable. The quadratic performance index of system (14) is obtained by integrating time on both sides of the inequality (17):

$$
J(t)=\int_{0}^{\infty}\left(Z^{T} Q Z+U^{T} R U\right) d t \leq V\left(Z_{0}\right)=Z_{0}^{T} P Z_{0} .
$$

Let $J^{*}=Z_{0}^{T} P Z_{0}$, where $J^{*}$ is an upper bound of the quadratic performance index. The symmetrical matrix $Y$ is defined as follows:

$$
Y=Q+(-G)^{T} R(-G)+\left(A-B_{2} G\right)^{T} P+P\left(A-B_{2} G\right)<0 .
$$

Then, inequality (15) is written as

$$
Y+P D F\left(E_{1}-E_{2} G\right)+\left(E_{1}-E_{2} G\right)^{T} F^{T}(P D)^{T}<0,
$$

where the matrix $F$ satisfies the condition $F^{T} F<I$.

If and only if there exists a positive constant $\mu$, the inequality (20) can be written as

$$
Y+\mu P D D^{T} P+\mu^{-1}\left(E_{1}-E_{2} G\right)^{T}\left(E_{1}-E_{2} G\right)<0 .
$$

The proof can be found in [34]. From Schur's complement [35], the inequality (21) is equivalent to

$$
\left[\begin{array}{cccc}
P\left(A-B_{2} G\right)+\left(A-B_{2} G\right)^{T} P+\mu P D D^{T} P & * & * & * \\
E_{1}-E_{2} G & -\mu I & * & * \\
I & 0 & -Q^{-1} & * \\
-G & 0 & 0 & -R^{-1}
\end{array}\right]<0 .
$$

The subelements " $*$ " of the upper matrix inequality are obtained according to the symmetry of the matrix. Inequality (22) is pre- and postmultiplying $\operatorname{diag}\left\{P^{-1}, I, I, I\right\}$. Let $X=P^{-1}$ and $W=-G P^{-1}$. When the following optimization is satisfied, a compensation controller based on the GCC algorithm is built for system (14):

$$
\begin{aligned}
\min _{\mu, W, X, M} & \operatorname{trace}(M), \\
\text { s.t. } & {\left[\begin{array}{cccc}
A X+B_{2} W+\left(A X+B_{2} W\right)^{T}+\mu D D^{T} & * & * & * \\
E_{1} X+E_{2} W & -\mu I & * & * \\
X & 0 & -Q^{-1} & * \\
W & 0 & 0 & -R^{-1}
\end{array}\right]<0, } \\
& {\left[\begin{array}{cc}
M & I \\
I & X
\end{array}\right]>0 . }
\end{aligned}
$$

The optimal solutions $\left(X^{\prime}\right.$ and $\left.W^{\prime}\right)$ are obtained through the solver (MINCX) in Matlab. Therefore, the optimal feedback gain matrix of uncertain system (14) is

$$
G=-W^{\prime}\left(X^{\prime}\right)^{-1} \text {. }
$$

The state feedback control law is

$$
u=W^{\prime}\left(X^{\prime}\right)^{-1} Z \text {. }
$$

In engineering practice, the measurement of displacement responses is very difficult for high-rise buildings. Compared to the displacement and velocity feedback, the acceleration feedback method is easier to be implemented. According to [31], a state observer based on structural acceleration responses is built for high-rise buildings in this paper. The simulink block diagram of the compensation controller is shown in Figure 5.

3.2. Numerical Verification. A compensation controller based on the GCC algorithm for the ten-storey frame is used 


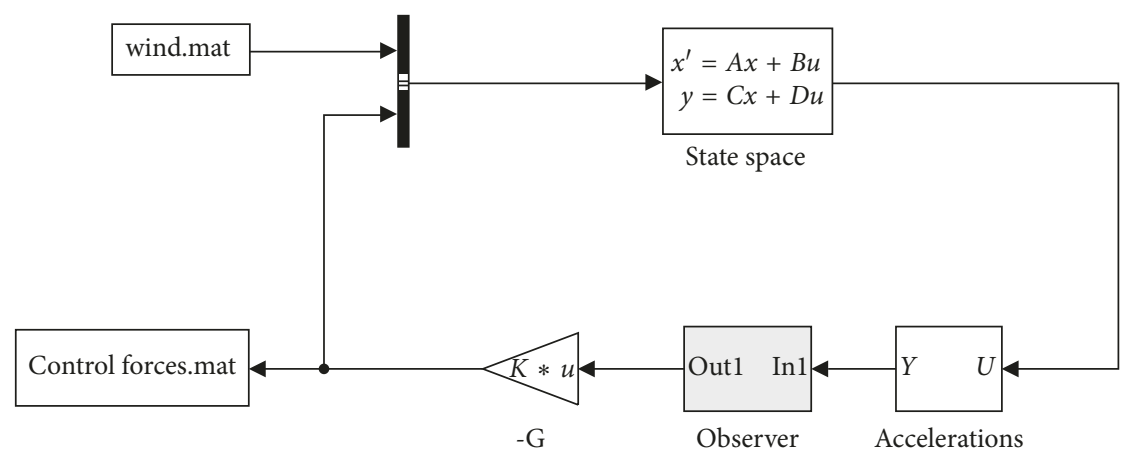

FIGURE 5: Simulink block diagram of the GCC compensation controller.

as an example. After adjusting, $Q_{8}, Q_{11}$, and $R$ are taken as $6 \times 10^{4}, 3 \times 10^{2}$, and $1 \times 10^{-3}$, respectively, and the weight coefficients of other floors are all defined as one. Two scenarios are analyzed in this part: (1) the variations of the structure parameters are $0 \%$, and (2) the variations of the stiffness and mass are $-30 \%$ and $20 \%$, respectively.

Under a ten-year return period wind load, the structural responses to the $8^{\text {th }}$ floor and the AMD parameters are shown in Figures 6 and 7. The corresponding control effects and AMD parameters are listed in Tables 2 and 3.

The results show that when parametric uncertainties are not considered, the compensation system based on the GCC algorithm reduces the wind vibration responses obviously. The control effects and AMD parameters of the GCC system (Table 2) are basically close to those of the LQR system (Table 1). Specifically, the maximum variations of the displacement, velocity, and acceleration control effects between two different systems are only $0.39 \%, 0.42 \%$, and $0.27 \%$, respectively, and the AMD parameters of the GCC controller increase by $0.16 \mathrm{kN}$ and $0.05 \mathrm{~cm}$.

When parametric uncertainties are considered, the GCC system is still effective. Comparing Table 2 with Table 3, the maximum variations of the displacement, velocity, and acceleration control effects between two different systems are only $1.98 \%, 2.25 \%$, and $4.80 \%$, respectively, and the AMD parameters of the GCC controller decrease by $0.39 \mathrm{kN}$ and increase by $0.15 \mathrm{~cm}$. Because the calculation process of the GCC controller contains the optimal selection for the control gains, its control forces display decreased slightly. When parametric uncertainties are considered, the strokes are little higher than that of the system without parametric uncertainties. Owing to the state vectors are real constants, the imaginary part of the feedback gain using GCC compensation is not zero and needs to be set as zero. There is no such problem in the LQR system.

\section{Experimental Verification}

The experimental system of the four-storey frame [36] (Figure 8 ) is considered as an example to verify the efficiency of the compensation control method presented in Section 3.

4.1. LQR System. The classical LQR controller is designed for the experimental system. Focusing on the control effects to the $4^{\text {th }}$ floor on which the auxiliary mass is located in and the strokes of the auxiliary mass, the suitable weight matrices $Q$ and $R$ are selected. Specifically, the weight coefficients $Q_{4}$ and $Q_{5}$, corresponding to the displacements of the top floor and the strokes of the auxiliary mass, are finally determined. After analysis, $Q_{4}, Q_{5}$, and $R$ are taken as $6 \times 10^{6}, 3 \times 10^{2}$, and $1 \times 10^{-3}$, respectively, and the weight coefficients of other floors are all defined as one.

Under an excitation load which has a frequency of $1 \mathrm{~Hz}$ and a peak value of $45.89 \mathrm{~N}$, the structural responses and AMD parameters of the LQR system are shown in Figure 9. The corresponding control effects and its AMD parameters are listed in Table 4. From Figure 9 and Table 4, the control effects to the $3^{\text {rd }}$ floor are less than those to the $2^{\text {nd }}$ and $4^{\text {th }}$ floors. In fact, the acceleration control needs a control force with a high frequency. As a result, the structural high-order modes are stimulated. The AMD device is placed on the $4^{\text {th }}$ floor, and the $3^{\text {rd }}$ floor has an opposite high-order phase with the $2^{\text {nd }}$ and $4^{\text {th }}$ floors. Because of the interaction between the control system and frame as well as the coupling between the horizontal and vertical vibrations, the dynamic responses do not completely obey a sine wave under a sinusoidal load. Moreover, the LQR control system can obviously reduce the dynamic responses. Owing to the selected weight matrices, the control effects to the $4^{\text {th }}$ floor are optimized firstly, in which its control effects are more obvious and better than that to other floors.

4.2. GCC System. The GCC compensation controller is designed for the experimental system. Two scenarios are analyzed in this part: (1) the variations of the structure parameters are $0 \%$, and (2) the variations of the stiffness and mass are $-38.3 \%$ and $16.8 \%$, respectively. The mass of each floor is changed by applying extra weight, and the stiffness is changed by adjusting the tightness of the connecting bolts. Under the above excitation load, the structural responses to the $4^{\text {th }}$ floor and the AMD parameters are shown in Figures 10 and 11. The corresponding control effects and AMD parameters are listed in Tables 5 and 6.

When parametric uncertainties are not considered, the GCC compensation system reduces the dynamic responses obviously. Its control effects and AMD parameters (Table 5) are basically close to those of the LQR system (Table 4). The maximum variations of the displacement and acceleration 


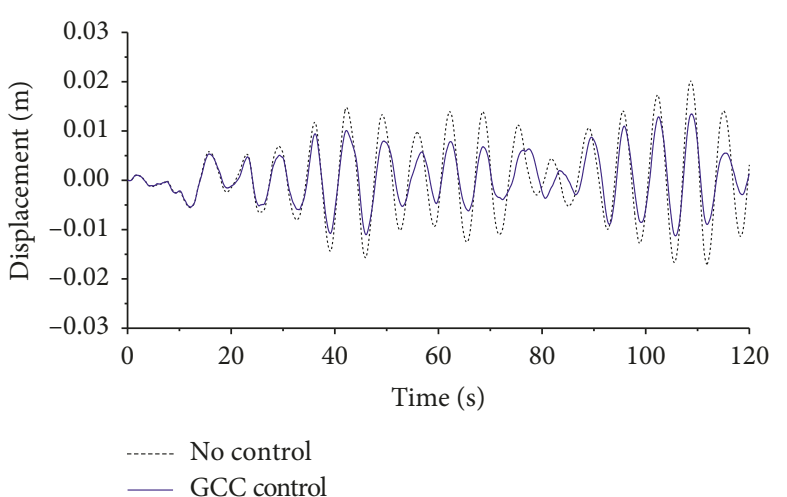

(a)

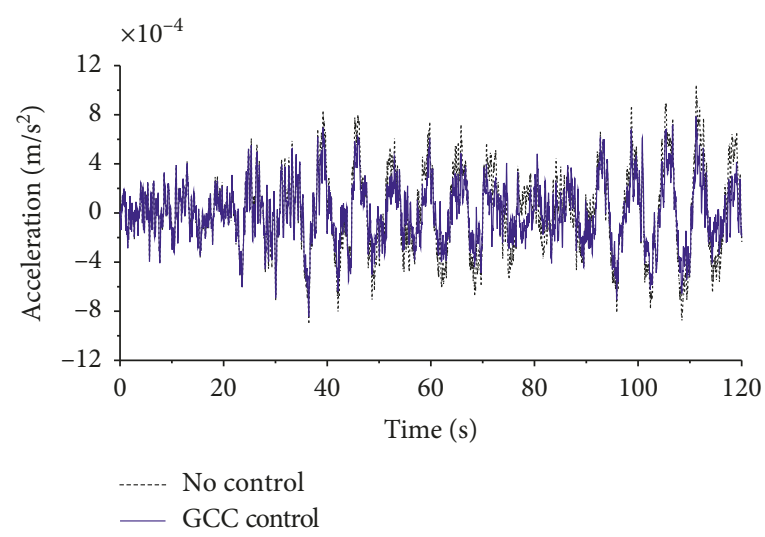

(c)

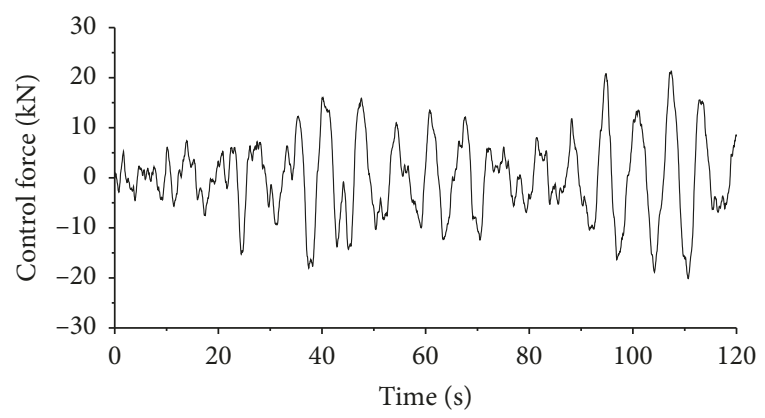

(e)

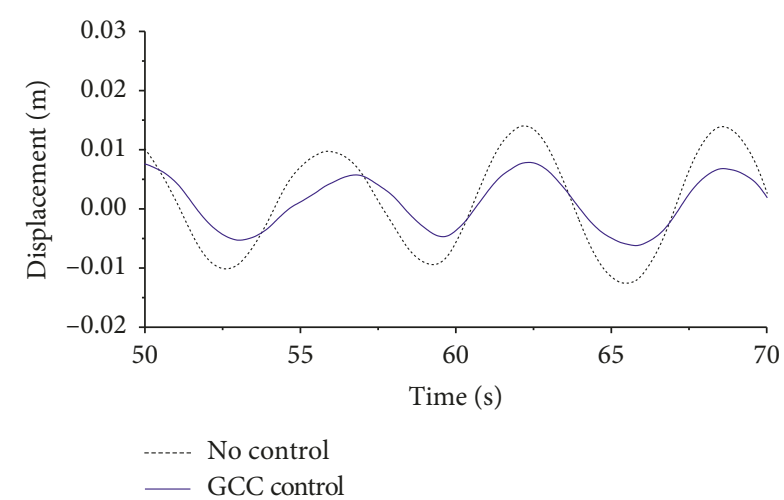

(b)

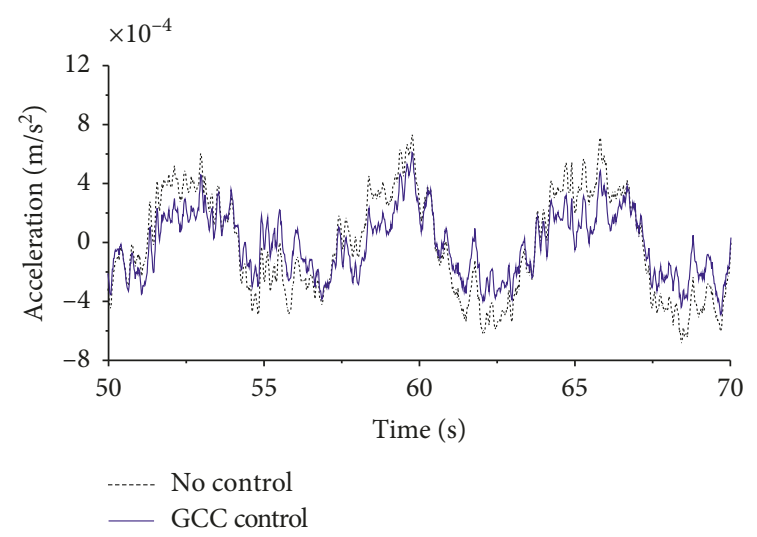

(d)

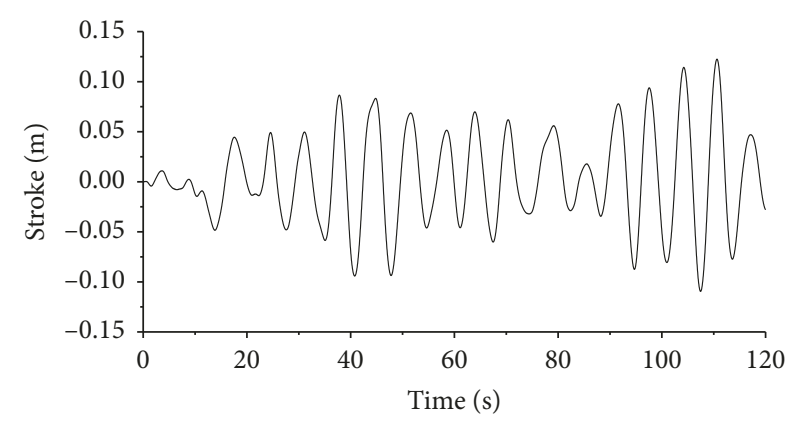

(f)

Figure 6: Comparison of the structural responses to the $8^{\text {th }}$ floor and the AMD parameters of the GCC system $\left(\delta_{K}=\delta_{M}=0 \%\right):(a) 0-120 \mathrm{~s}$ and (b) 50-70 s displacements; (c) 0-120 s and (d) 50-70 s accelerations; (e) control forces; (f) strokes.

control effects between two different systems are only $2.11 \%$ and $3.18 \%$, respectively, and the AMD parameters of the GCC controller increase by $0.51 \mathrm{~N}$ and $0.18 \mathrm{~cm}$. The results are consistent with the numerical analysis in Section 3.2. When parametric uncertainties are considered, the GCC system is still effective. Specifically, the maximum variations of the displacement and acceleration control effects between two different systems (Tables 5 and 6) are only $0.93 \%$ and $4.18 \%$, respectively, and the AMD parameters of the GCC controller decrease by $0.49 \mathrm{~N}$ and increase by $0.84 \mathrm{~cm}$. The reason is explained from the numerical verification in Section 3.2.

\section{Conclusion}

Based on a Lyapunov stability theory and LMI approach, a compensation controller based on the GCC algorithm is presented for an uncertain control system. A numerical example and an experiment have been conducted to verify the effectiveness of the proposed method. Based on the results, the following conclusions can be made:

(1) The suitable weight matrices are obtained according to the numerical analysis. Based on these weight matrices, the LQR control system can obviously reduce the wind vibration responses. 

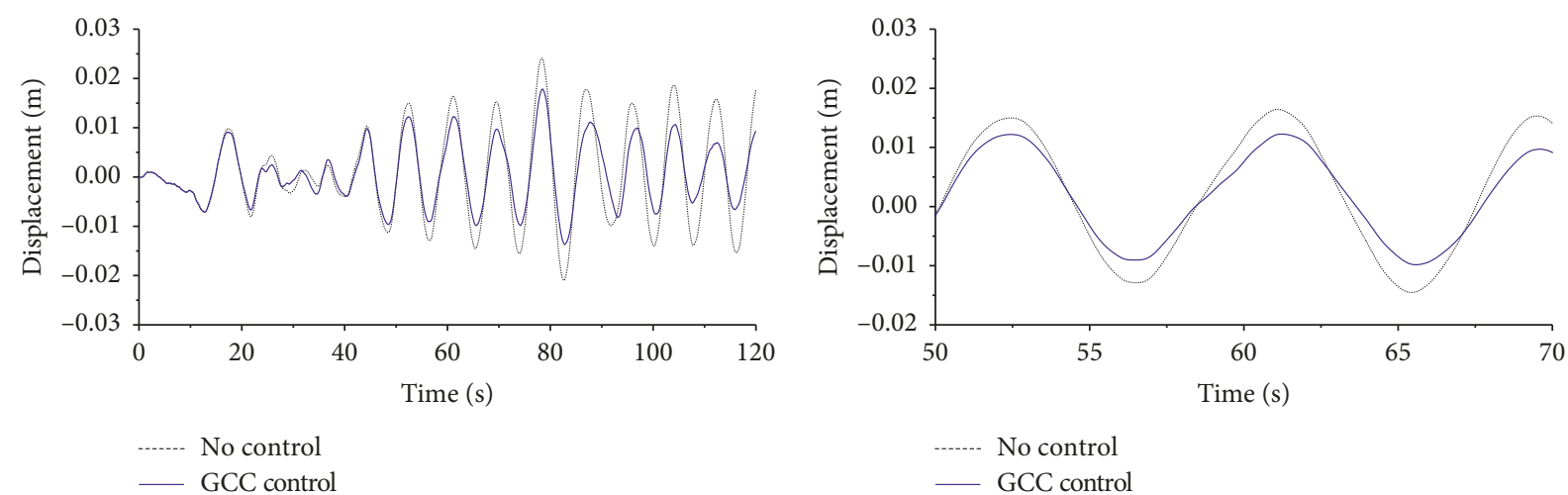

(a)

(b)

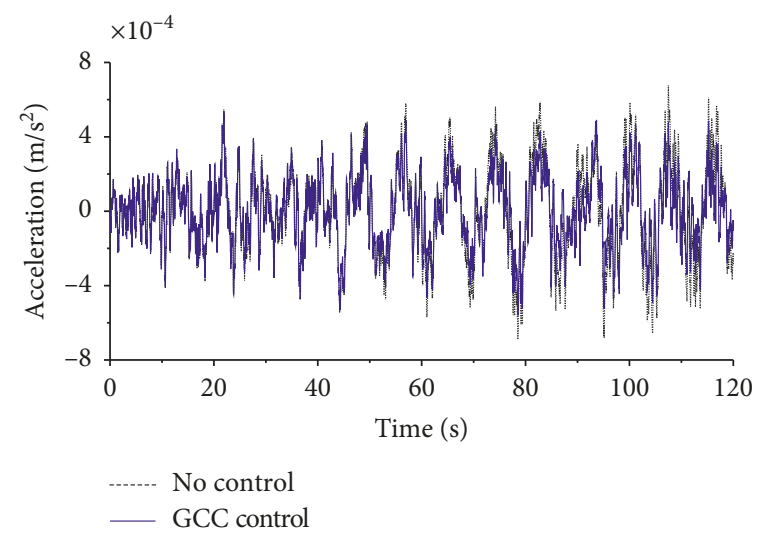

(c)

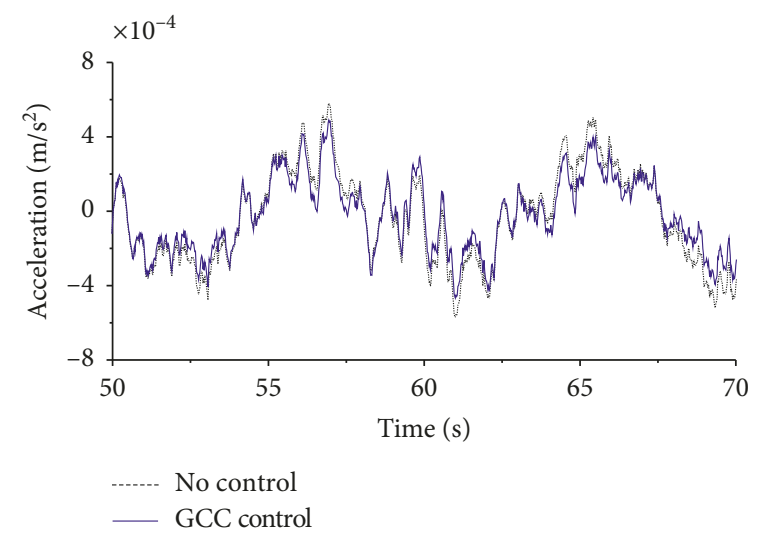

(d)
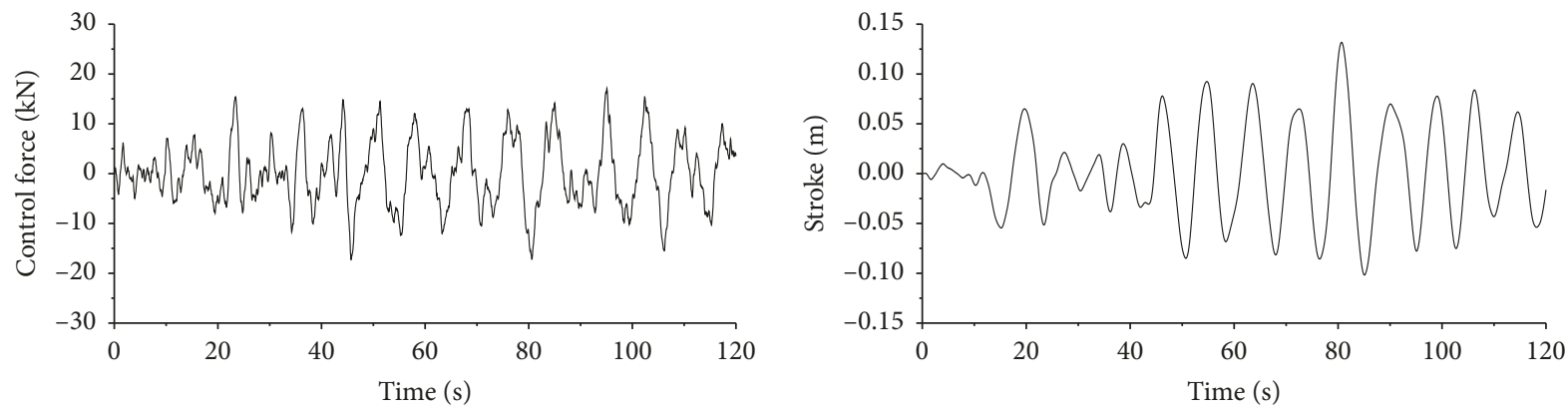

(e)

(f)

FIgURE 7: Comparison of the structural responses to the $8^{\text {th }}$ floor and the AMD parameters of the GCC system $\left(\delta_{K}=-30 \%, \delta_{M}=20 \%\right)$ : (a) 0-120 s and (b) 50-70 s displacements; (c) 0-120 s and (d) 50-70 s accelerations; (e) control forces; (f) strokes.

TABLE 2: Control effects to the structural responses of the frame without variations under GCC control.

\begin{tabular}{|c|c|c|c|c|}
\hline \multicolumn{2}{|c|}{ Index } & \multicolumn{3}{|c|}{ No variations $\left(\delta_{K}=\delta_{M}=0 \%\right)$} \\
\hline & & No control & Control & Effect (\%) \\
\hline \multirow{3}{*}{ Displacement $(\mathrm{mm})$} & $8^{\text {th }}$ floor & 7.91 & 5.18 & 34.56 \\
\hline & $9^{\text {th }}$ floor & 8.39 & 5.49 & 34.53 \\
\hline & $10^{\text {th }}$ floor & 8.69 & 5.69 & 34.49 \\
\hline \multirow{3}{*}{ Velocity $(\mathrm{mm} / \mathrm{s})$} & $8^{\text {th }}$ floor & 1.52 & 0.99 & 34.84 \\
\hline & $9^{\text {th }}$ floor & 1.62 & 1.07 & 34.31 \\
\hline & $10^{\text {th }}$ floor & 1.69 & 1.13 & 33.57 \\
\hline \multirow{3}{*}{ Acceleration $\left(\mathrm{mm} / \mathrm{s}^{2}\right)$} & $8^{\text {th }}$ floor & 0.33 & 0.24 & 25.67 \\
\hline & $9^{\text {th }}$ floor & 0.36 & 0.27 & 24.38 \\
\hline & $10^{\text {th }}$ floor & 0.41 & 0.33 & 19.70 \\
\hline Control force $(\mathrm{kN})$ & & - & 7.97 & - \\
\hline Stroke $(\mathrm{cm})$ & & - & 4.63 & - \\
\hline
\end{tabular}


TABLE 3: Control effects to the structural responses of the frame with variations under GCC control.

\begin{tabular}{|c|c|c|c|c|}
\hline \multicolumn{2}{|c|}{ Index } & \multicolumn{3}{|c|}{ With variations $\left(\delta_{K}=-30 \%, \delta_{M}=20 \%\right)$} \\
\hline & & No control & Control & Effect $(\%)$ \\
\hline \multirow{3}{*}{ Displacement (mm) } & $8^{\text {th }}$ floor & 9.29 & 6.25 & 32.70 \\
\hline & $9^{\text {th }}$ floor & 9.85 & 6.63 & 32.61 \\
\hline & $10^{\text {th }}$ floor & 10.20 & 6.88 & 32.51 \\
\hline \multirow{3}{*}{ Velocity (mm/s) } & $8^{\text {th }}$ floor & 1.38 & 0.92 & 33.06 \\
\hline & $9^{\text {th }}$ floor & 1.48 & 1.00 & 32.31 \\
\hline & $10^{\text {th }}$ floor & 1.55 & 1.07 & 31.32 \\
\hline \multirow{3}{*}{ Acceleration $\left(\mathrm{mm} / \mathrm{s}^{2}\right)$} & $8^{\text {th }}$ floor & 0.24 & 0.19 & 20.87 \\
\hline & $9^{\text {th }}$ floor & 0.27 & 0.21 & 20.27 \\
\hline & $10^{\text {th }}$ floor & 0.31 & 0.26 & 16.58 \\
\hline Control force $(\mathrm{kN})$ & & - & 7.58 & - \\
\hline Stroke $(\mathrm{cm})$ & & - & 4.78 & - \\
\hline
\end{tabular}

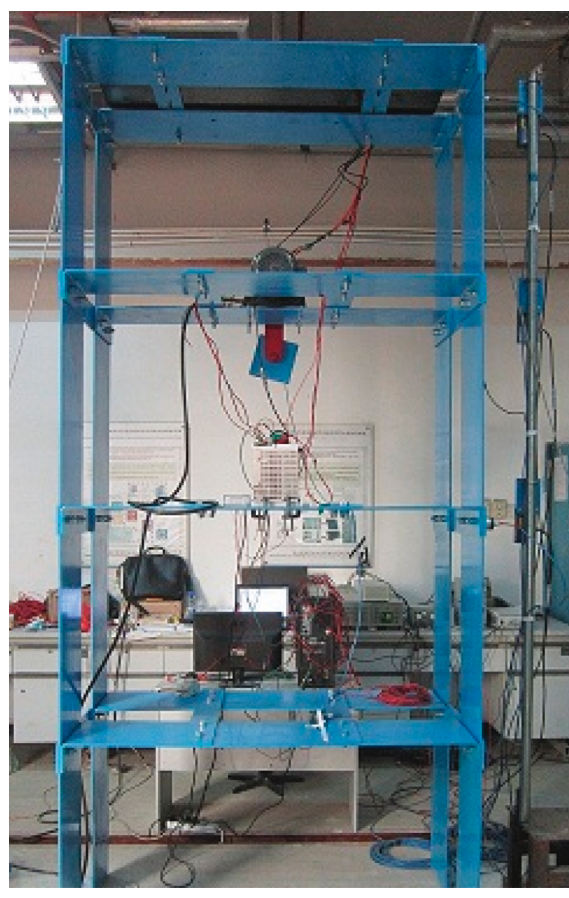

(a)

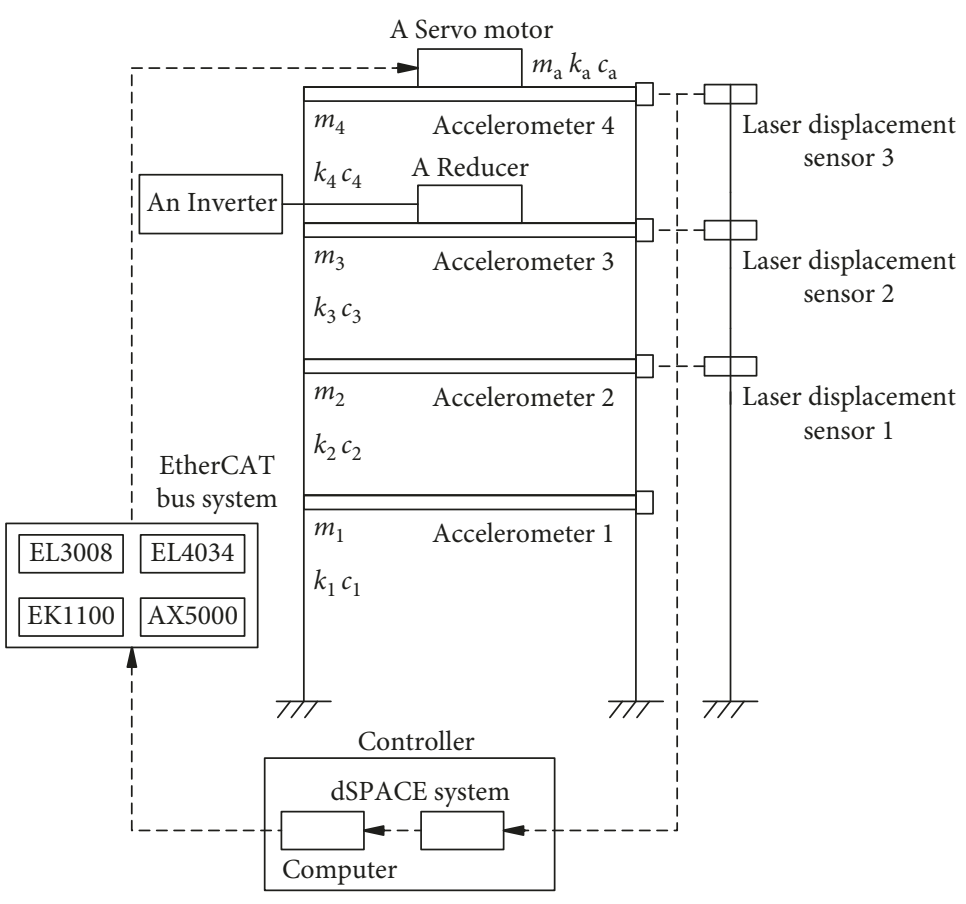

(b)

Figure 8: Pictures of the steel frame structure: (a) photo; (b) schematic.

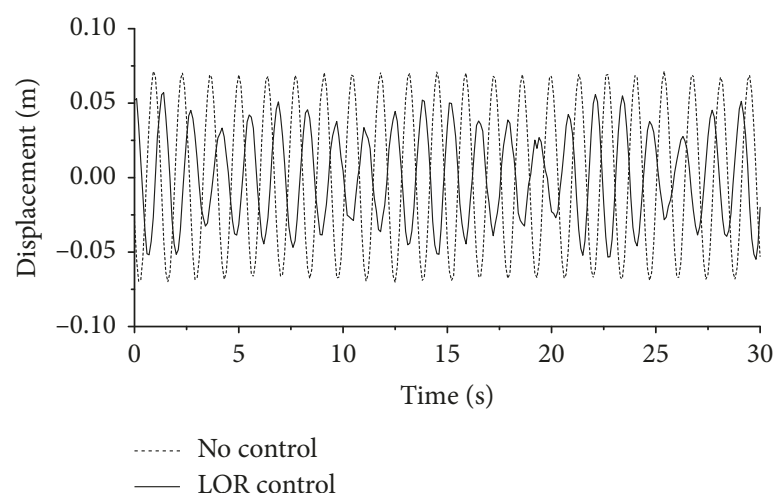

(a)

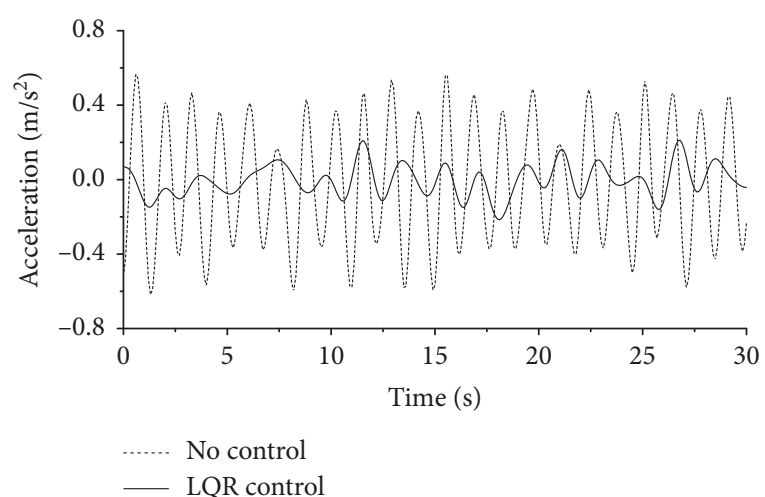

(b)

Figure 9: Continued. 


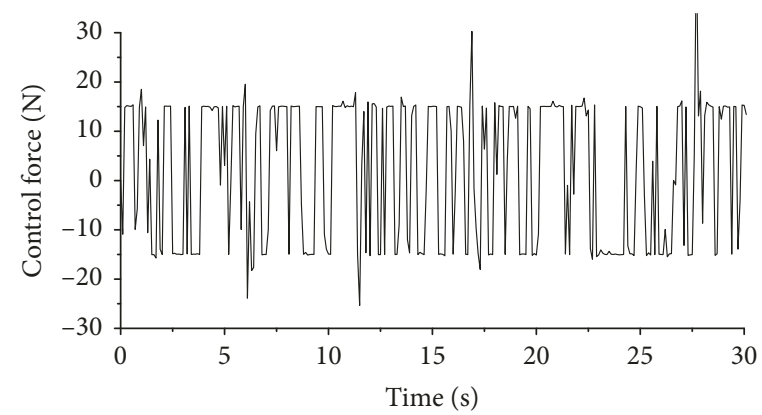

(c)

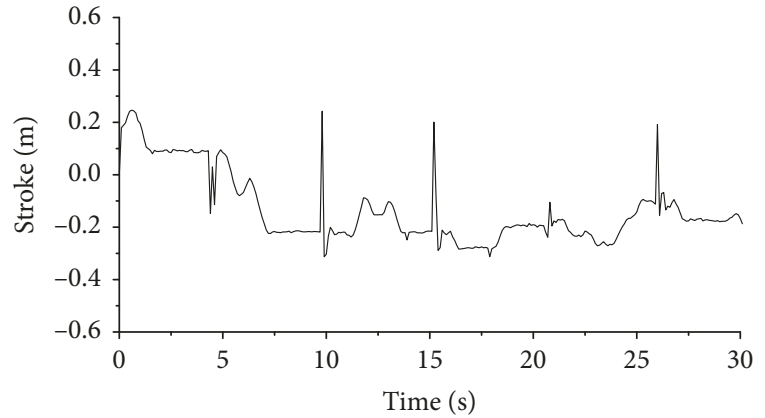

(d)

FIgURE 9: Comparison of the structural responses to the $4^{\text {th }}$ floor and the AMD parameters of the LQR system: (a) displacements; (b) accelerations; (c) control forces; (d) the strokes.

TABLE 4: Control effects to the structural responses of the experimental system without variations under LQR control.

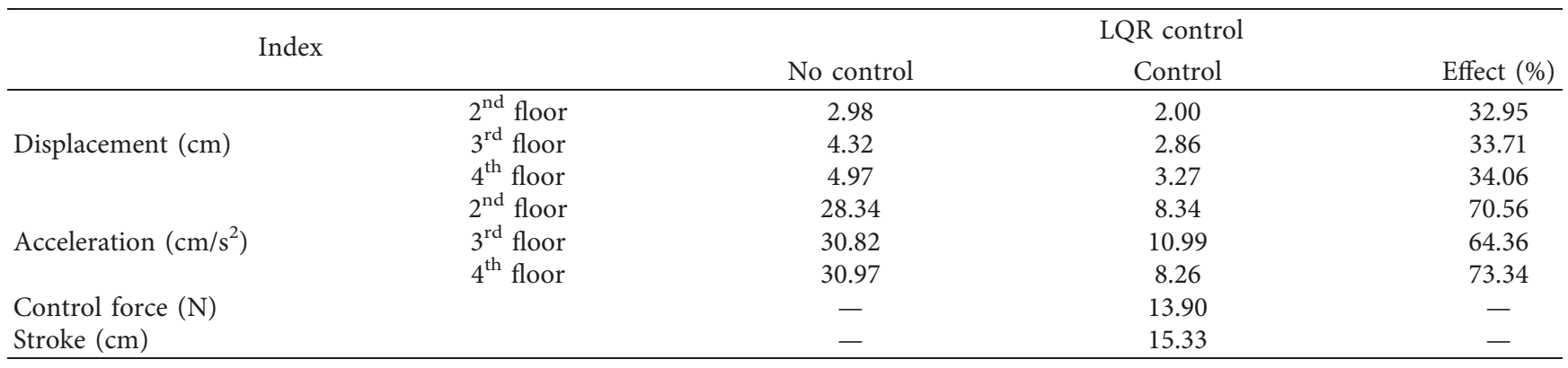

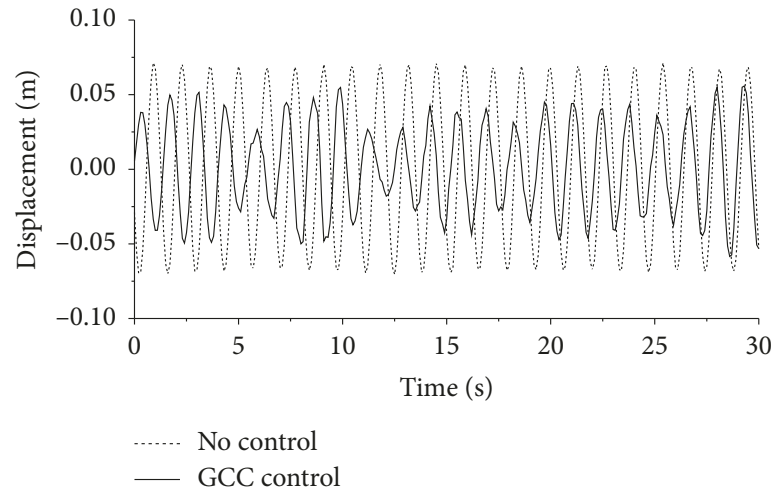

(a)

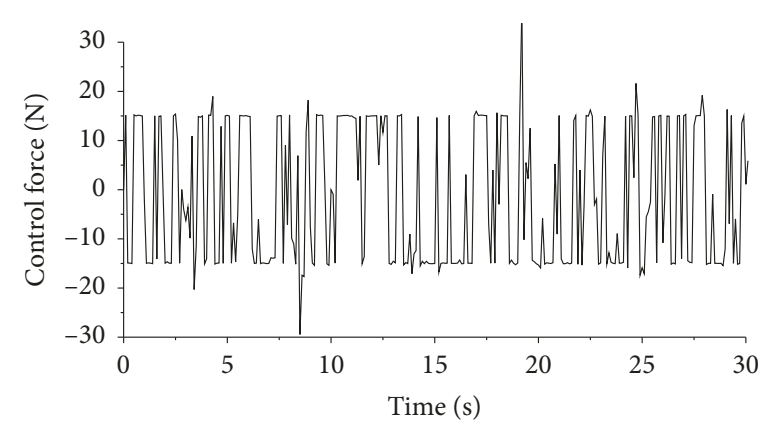

(c)

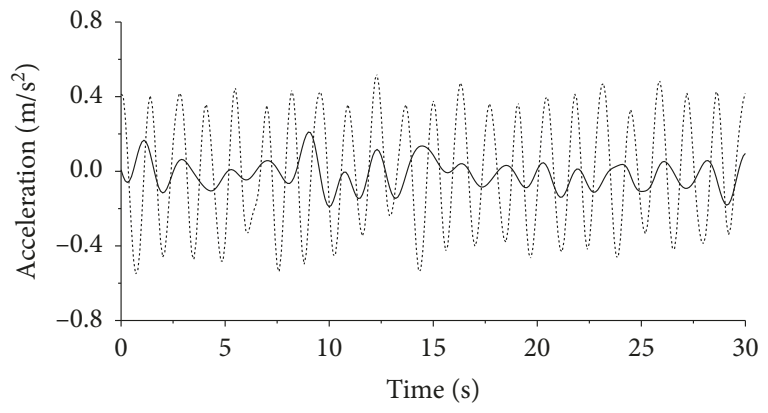

-..... No control

— GCC control

(b)

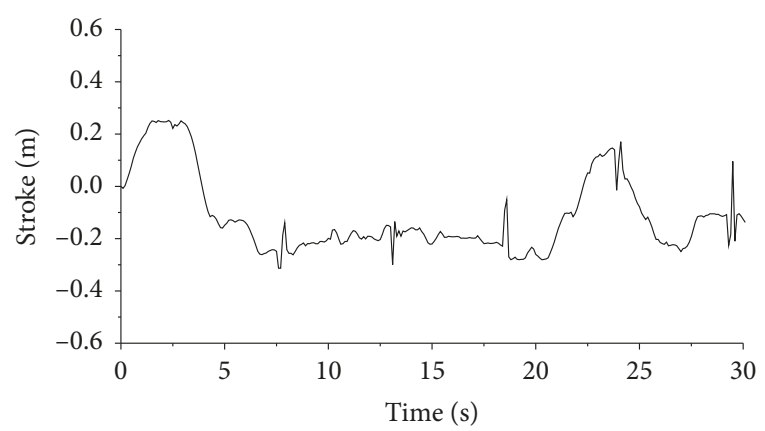

(d)

FIGURE 10: Comparison of the structural responses to the $4^{\text {th }}$ floor and the AMD parameters of the GCC system $\left(\delta_{K}=\delta_{M}=0 \%\right):(a)$ displacements; (b) accelerations; (c) control forces; (d) the strokes. 


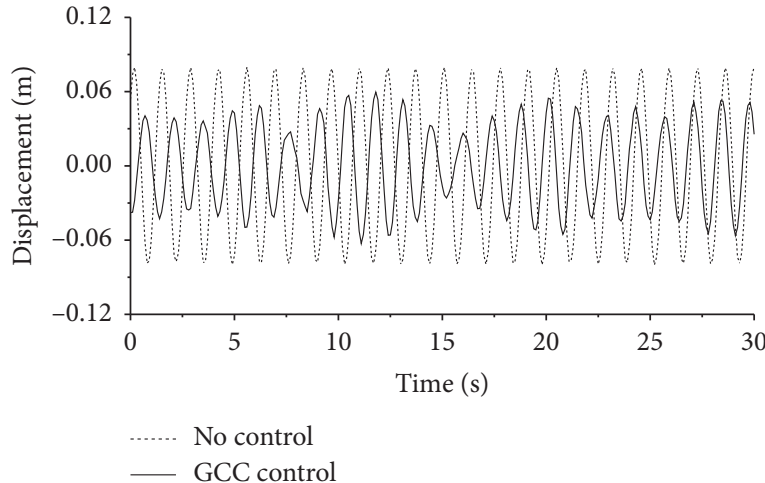

(a)

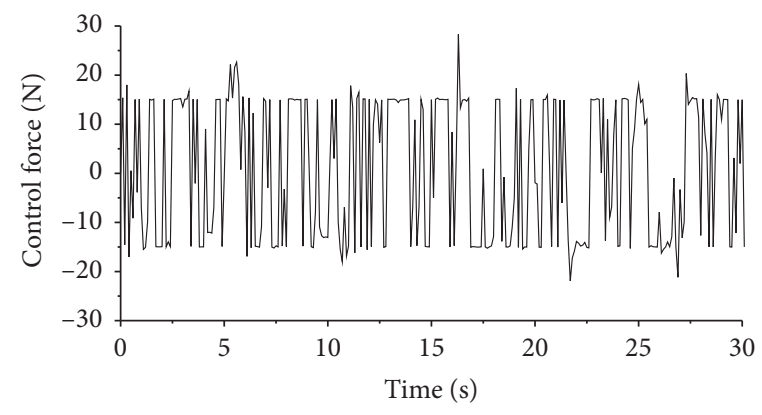

(c)

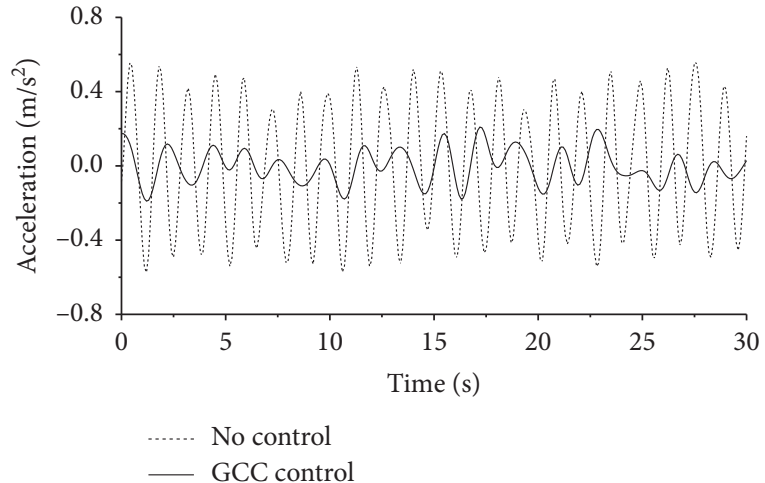

(b)

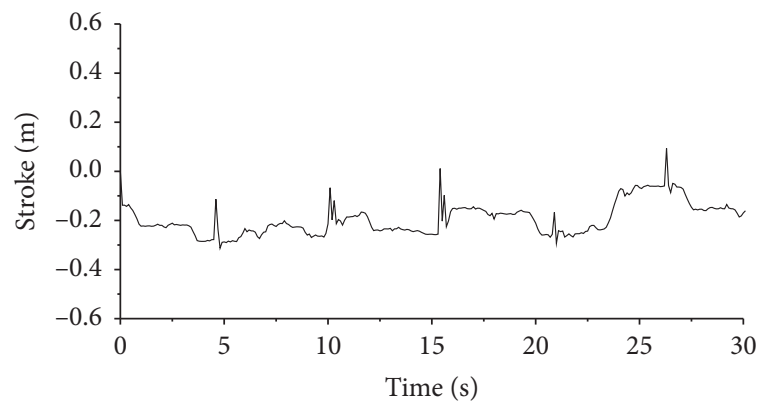

(d)

Figure 11: Comparison of the structural responses to the $4^{\text {th }}$ floor and the AMD parameters of the GCC system $\left(\delta_{K}=-38.3 \%, \delta_{M}=16.8 \%\right)$ : (a) displacements; (b) accelerations; (c) control forces; (d) strokes.

TABLE 5: Control effects to the structural responses of the experimental system without variations under GCC control.

\begin{tabular}{|c|c|c|c|c|}
\hline \multirow{2}{*}{\multicolumn{2}{|c|}{ Index }} & \multicolumn{3}{|c|}{ No variations $\left(\delta_{K}=\delta_{M}=0 \%\right)$} \\
\hline & & No control & Control & Effect (\%) \\
\hline \multirow{3}{*}{ Displacement $(\mathrm{cm})$} & $2^{\text {nd }}$ floor & 2.98 & 2.05 & 31.06 \\
\hline & $3^{\text {rd }}$ floor & 4.32 & 2.95 & 31.71 \\
\hline & $4^{\text {th }}$ floor & 4.97 & 3.38 & 31.95 \\
\hline \multirow{3}{*}{ Acceleration $\left(\mathrm{cm} / \mathrm{s}^{2}\right)$} & $2^{\text {nd }}$ floor & 28.34 & 8.32 & 70.63 \\
\hline & $3^{\text {rd }}$ floor & 30.82 & 10.01 & 67.54 \\
\hline & $4^{\text {th }}$ floor & 30.97 & 7.56 & 75.59 \\
\hline Control force $(\mathrm{N})$ & & - & 14.41 & - \\
\hline Stroke $(\mathrm{cm})$ & & - & 15.51 & - \\
\hline
\end{tabular}

TABLE 6: Control effects to the structural responses of the experimental system with variations under GCC control.

\begin{tabular}{|c|c|c|c|c|}
\hline \multicolumn{2}{|c|}{ Index } & \multicolumn{3}{|c|}{ No variations $\left(\delta_{K}=-38.3 \%, \delta_{M}=16.8 \%\right)$} \\
\hline & & \multirow{2}{*}{$\begin{array}{c}\text { No control } \\
3.35\end{array}$} & \multirow{2}{*}{$\begin{array}{c}\text { Control } \\
2.28\end{array}$} & \multirow{2}{*}{$\frac{\text { Effect }(\%)}{31.90}$} \\
\hline \multirow{3}{*}{ Displacement $(\mathrm{cm})$} & $2^{\text {nd }}$ floor & & & \\
\hline & $3^{\text {rd }}$ floor & 4.91 & 3.32 & 32.31 \\
\hline & $4^{\text {th }}$ floor & 5.63 & 3.78 & 32.88 \\
\hline \multirow{3}{*}{ Acceleration $\left(\mathrm{cm} / \mathrm{s}^{2}\right)$} & $2^{\text {nd }}$ floor & 41.05 & 10.34 & 74.81 \\
\hline & $3^{\text {rd }}$ floor & 35.01 & 11.12 & 68.24 \\
\hline & $4^{\text {th }}$ floor & 34.26 & 8.36 & 75.58 \\
\hline Control force $(\mathrm{N})$ & & - & 13.92 & - \\
\hline Stroke $(\mathrm{cm})$ & & - & 16.35 & - \\
\hline
\end{tabular}

(2) Based on these weight matrices, the GCC control system reduces the wind vibration responses obviously when parametric uncertainties are not considered. The control effects and AMD parameters of the GCC system are basically close to those of the LQR system. 
(3) For the control system with parametric uncertainties, the GCC compensation controller improves its performance largely and keeps its control parameters stable, which is close to the system without parametric uncertainties.

(4) The same result can be obtained when this compensation controller is applied to the experimental system with parametric uncertainties.

Based on the GCC algorithm, a new state feedback controller achieves compensating parametric uncertainties in high-rise buildings with an AMD system. The results indicated that the controller has a good performance and a stable control parameter, which provide good potential for structural vibration control of high-rise buildings.

\section{Data Availability}

All data generated and analyzed during this study are included in this published article.

\section{Conflicts of Interest}

The authors declare that they have no conflicts of interest.

\section{Authors' Contributions}

Zuohua Li and Chaojun Chen contributed equally to this work. Chaojun Chen wrote the paper and summarized the results. Zuohua $\mathrm{Li}$ and Jun Teng participated in the data analysis and conceived the study. Junkai Dong and Beichun Lin reviewed the study plan and corrected the grammatical mistakes.

\section{Acknowledgments}

The research described in this paper was financially supported by the National Key Research and Development Program of China (Grant no. 2016YFC0701102), the China Postdoctoral Science Foundation Grant (Grant no. 2019M651291), the National Major Scientific Research Instrument Development Program of China (Grant no. 51827811), the National Natural Science Foundations of China (Grant no. 51538003), and the Shenzhen Technology Innovation Programs (Grant nos. JCYJ20170811160003571 and JCYJ20180508152238111).

\section{References}

[1] W. Shen, S. Zhu, and H. Zhu, "Unify energy harvesting and vibration control functions in randomly excited structures with electromagnetic devices," Journal of Engineering $\mathrm{Me}$ chanics, vol. 145, article 040181151, 2019.

[2] W. Shen, S. Zhu, Y.-L. Xu, and H.-p. Zhu, "Energy regenerative tuned mass dampers in high-rise buildings," Structural Control and Health Monitoring, vol. 25, no. 2, p. e2072, 2018.

[3] Y. Yang and C. Li, "Performance of tuned tandem mass dampers for structures under the ground acceleration," Structural Control and Health Monitoring, vol. 24, no. 10, p. e1974, 2017.
[4] B. Basu, O. S. Bursi, F. Casciati et al., "A European Association for the Control of Structures joint perspective. Recent studies in civil structural control across Europe," Structural Control and Health Monitoring, vol. 21, no. 12, pp. 1414-1436, 2014.

[5] C. Zhang and J. Ou, "Modeling and dynamical performance of the electromagnetic mass driver system for structural vibration control," Engineering Structures, vol. 82, pp. 93-103, 2015.

[6] H. Xu, C. Zhang, H. Li, and J. Ou, "Real-time hybrid simulation approach for performance validation of structural active control systems: a linear motor actuator based active mass driver case study," Structural Control and Health Monitoring, vol. 21, no. 4, pp. 574-589, 2014.

[7] S. Y. Zhu, W. A. Shen, and Y. L. Xu, "Linear electromagnetic devices for vibration damping and energy harvesting: modeling and testing," Engineering Structures, vol. 34, pp. 198-212, 2012.

[8] J. P. Ou, Active, Semi-Active and Intelligent Control in Civil Engineering Structure, Science Press, Beijing, China, 2003.

[9] C. X. Li and X. H. Gu, "Design of fluid viscous dampers for single-story asymmetric-plan buildings based on LQR theory," in Proceedings of the International Conference on Computer Modeling and Simulation, pp. 49-53, Sanya, China, January 2010.

[10] N. Zhao, L. S. Hou, C. X. Qu et al., "Study on nonlinear vibration control of structures considering parameters uncertainties," Journal of Disaster Prevention and Mitigation Engineering, vol. 35, no. 4, pp. 477-483, 2015.

[11] G. Hu, Y. Q. Liu, and Y. Q. Li, "The cause of formation, the classification and the control strategy for uncertainty control systems," Industrial Engineering Journal, vol. 1, pp. 49-52, 2001.

[12] Y. Chen and A.-K. Xue, "Improved stability criterion for uncertain stochastic delay systems with nonlinear uncertainties," Electronics Letters, vol. 44, no. 7, pp. 458-459, 2008.

[13] S. Xu and T. Chen, "HoHo output feedback control for uncertain stochastic systems with time-varying delays," Automatica, vol. 40, no. 12, pp. 2091-2098, 2004.

[14] S. Y. Xu, J. Lam, G. H. Yang, and J. L. Wang, "Stabilization and $\mathrm{H}$-infinity control for uncertain stochastic time-delay systems via non-fragile controllers," Asian Journal of Control, vol. 8, no. 2, pp. 197-200, 2006.

[15] H. L. Liu, G. R. Duan, and L. Y. Fan, "Delay-dependent passive control of stochastic differential system with time delay," in Proceedings of the 2010 8th World Congress on Intelligent Control and Automation (WCICA), pp. 963-968, Jinan, China, July 2010.

[16] S. Chang and T. Peng, "Adaptive guaranteed cost control of systems with uncertain parameters," IEEE Transactions on Automatic Control, vol. 17, no. 4, pp. 474-483, 1972.

[17] B. Shen, Z. Wang, and H. Tan, "Guaranteed cost control for uncertain nonlinear systems with mixed time-delays: the discrete-time case," European Journal of Control, vol. 40, pp. 62-67, 2018.

[18] X. Zhou, T. Dong, X. Tang, C. Yang, and W. Gui, “A BMI approach to guaranteed cost control of discrete-time uncertain system with both state and input delays," Optimal Control Applications and Methods, vol. 36, no. 6, pp. 844-852, 2015.

[19] E. Cheres, Z. J. Palmor, and S. Gutman, "Quantitative measures of robustness for systems including delayed perturbations," IEEE Transactions on Automatic Control, vol. 34, no. 11, pp. 1203-1204, 1989. 
[20] H. S. Wu and K. Mizukami, "Robust stabilization of uncertain linear dynamical systems with time-varying delay," Journal of Optimization Theory and Applications, vol. 82, no. 3, pp. 593-606, 1994.

[21] S. O. R. Moheimani and I. R. Petersen, "Optimal quadratic guaranteed cost control of a class of uncertain time-delay systems," IEE Proceedings-Control Theory and Applications, vol. 144, no. 2, pp. 183-188, 1997.

[22] S. Boyd, L. E. Ghaoui, E. Feron, and V. Balakrishnan, Linear Matrix Inequalities in System and Control Theory, Society for Industrial and Applied Mathematics (SIAM), Philadelphia, PA, USA, 1994.

[23] S. Guo, "Robust reliability method for non-fragile guaranteed cost control of parametric uncertain systems," Systems and Control Letters, vol. 64, pp. 27-35, 2014.

[24] Z. Pu and R. Rao, "Delay-dependent LMI-based robust stability criterion for discrete and distributed time-delays Markovian jumping reaction-diffusion CGNNs under Neumann boundary value," Neurocomputing, vol. 171, pp. 13671374, 2016.

[25] S. Mobayen, "An LMI-based robust tracker for uncertain linear systems with multiple time-varying delays using optimal composite nonlinear feedback technique," Nonlinear Dynamics, vol. 80, no. 1-2, pp. 917-927, 2015.

[26] A. Ahmadi and M. Aldeen, "An LMI approach to the design of robust delay-dependent overlapping load frequency control of uncertain power systems," International Journal of Electrical Power and Energy Systems, vol. 81, pp. 48-63, 2016.

[27] K.-H. Kim, M.-J. Park, O.-M. Kwon, S.-M. Lee, and E.-J. Cha, "Stability and robust HoControl for time-delayed systems with parameter uncertainties and stochastic disturbances," Journal of Electrical Engineering and Technology, vol. 11, no. 1, pp. 200-214, 2016.

[28] C. Chen, Z. Li, J. Teng, and Y. Wang, "Influence analysis of a Higher-Order CSI effect on AMD systems and its TimeVarying delay compensation using a guaranteed cost control algorithm," Applied Sciences, vol. 7, no. 4, p. 313, 2017.

[29] Z. Li, C. Chen, J. Teng, and Y. Wang, "A compensation controller based on a regional pole-assignment method for AMD control systems with a time-varying delay," Journal of Sound and Vibration, vol. 419, pp. 18-32, 2018.

[30] E. J. Hannan, "The identification of vector mixed autoregressivemoving average systems," Biometrika, vol. 56, no. 1, pp. 223225, 1969.

[31] C.-J. Chen, Z.-H. Li, J. Teng, W.-H. Hu, and Y. Wang, “An observer-based controller with a LMI-based filter against wind-induced motion for high-rise buildings," Shock and Vibration, vol. 2017, pp. 1-18, 2017.

[32] P. P. Khargonekar, I. R. Petersen, and K. Zhou, "Robust stabilization of uncertain linear systems: quadratic stabilizability and H/sup infinity/control theory," IEEE Transactions on Automatic Control, vol. 35, no. 3, pp. 356-361, 1990.

[33] S. Sastry, Lyapunov Stability Theory, Springer-Verlag New York, Inc., New York, NY, USA, 1999.

[34] L. Xie, "Output feedback Ho control of systems with parameter uncertainty," International Journal of Control, vol. 63, no. 4, pp. 741-750, 1996.

[35] F. Zhang, The Schur Complement and its Applications, Springer, Heidelberg, Germany, 2005.

[36] J. Teng, H. B. Xing, W. Lu, Z. H. Li, and C. J. Chen, "Influence analysis of time delay to active mass damper control system using pole assignment method," Mechanical Systems and Signal Processing, vol. 80, pp. 99-116, 2016. 


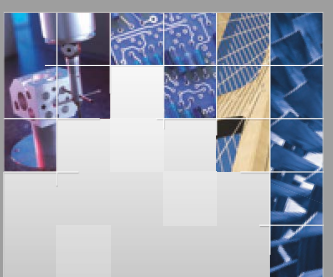

\section{Enfincering}
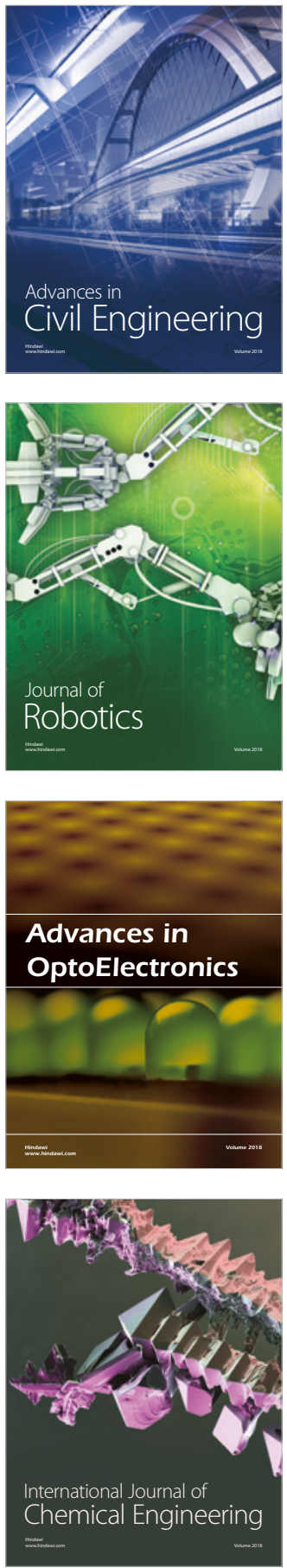

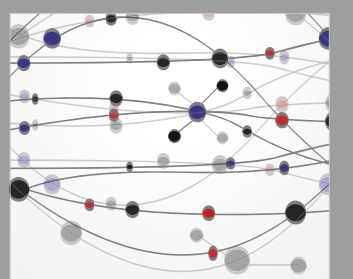

\section{Rotating \\ Machinery}

The Scientific World Journal

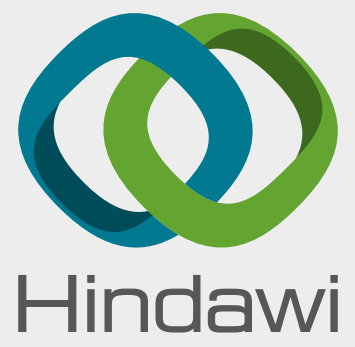

Submit your manuscripts at

www.hindawi.com
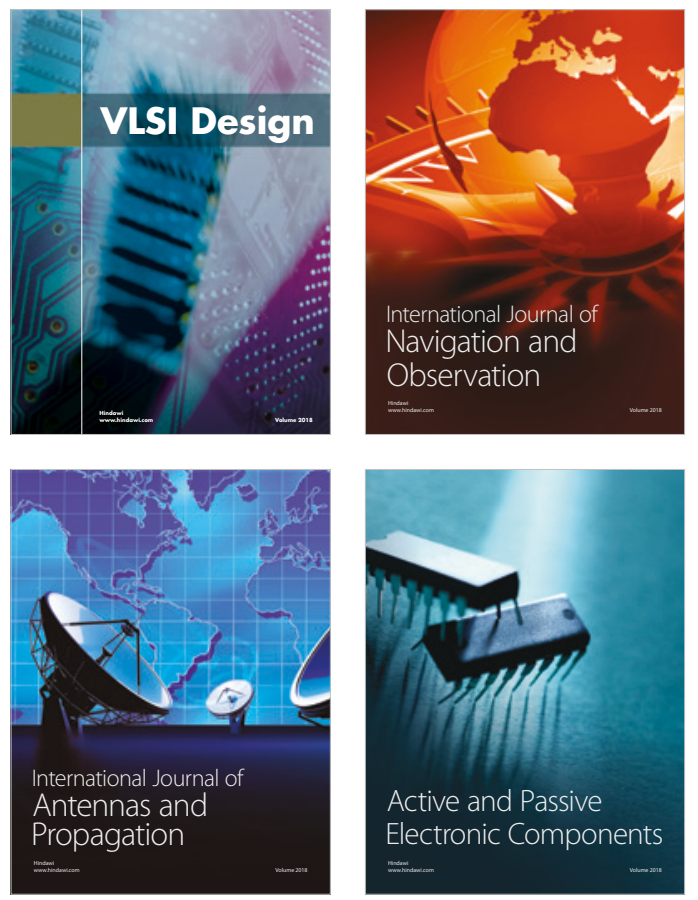
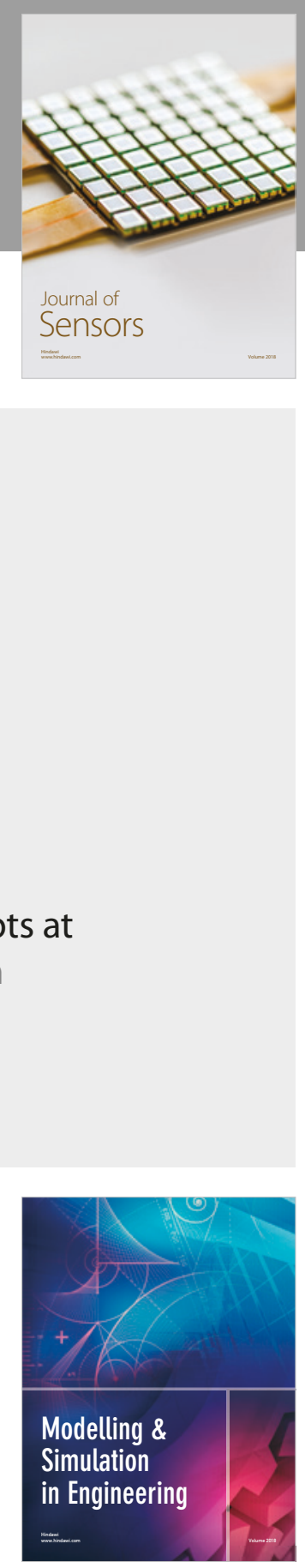

\section{Advances \\ Multimedia}
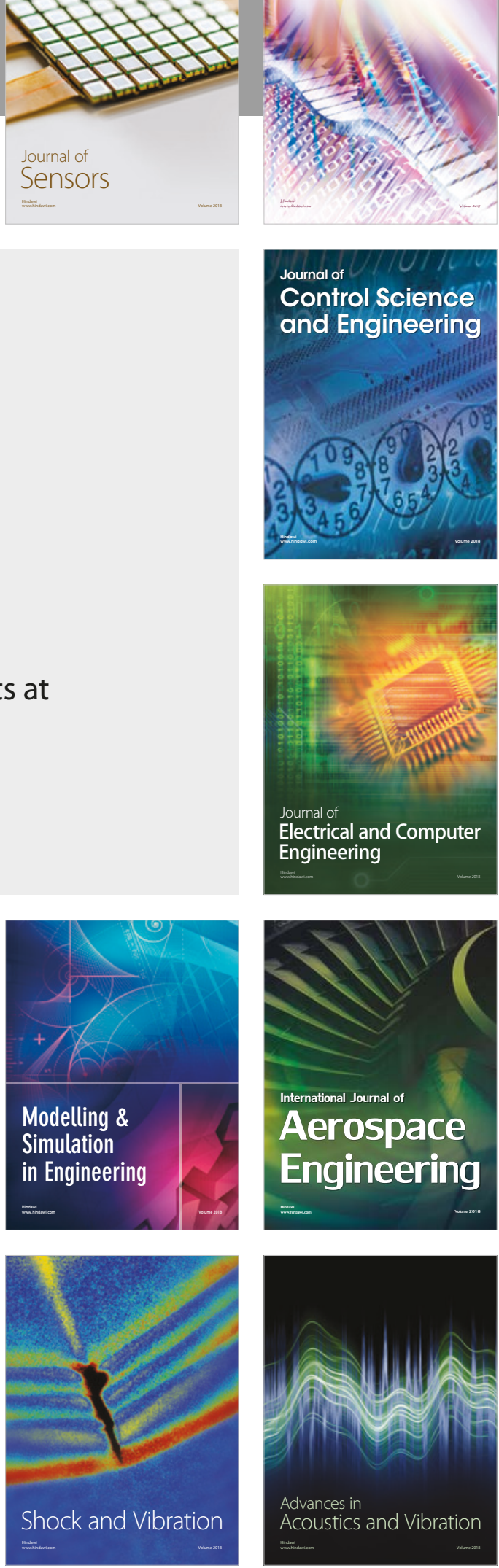